\title{
Ensino de história e cinema: indícios e reflexões sobre nomes, lugar social e campo de pesquisa (ENPEH - 1995/2013)
} History Teaching and Cinema: Vestiges and Reflections on Names, Social Position and Research Field (ENPEH - 1995/2013)

\author{
Humberto Perinelli Neto* \\ Mariana de Oliveira Brandolezi** \\ Ricardo Scucuglia Rodrigues da Silva ${ }^{* * *}$ \\ Edilson Moreira de Oliveira ${ }^{* * *}$
}

\begin{abstract}
Resumo
O ensino de História está contido na cultura escolar e, como tal, configura amplo campo de pesquisa. É possível identificar diversos estudos que se debruçam sobre novas formas de ensinar História, inclusive o diálogo envolvendo cinema. $\mathrm{O}$ artigo promove uma investigação científica baseada em levantamento bibliográfico e entendimento dos trabalhos dedicados ao diálogo entre ensino de História e cinema publicados nos Anais do Encontro Nacional de Pesquisadores do Ensino de História (ENPEH) entre 1995 e 2013, visando compreender características desse campo/lugar social de pesquisa por meio de análise indiciária dos autores, tendo em vista exploração do currículo Lattes.
\end{abstract}

\begin{abstract}
The teaching of History is contained in the school culture and configures a wide field of research. It is possible to identify several studies that are based on new ways of teaching history, including the dialogue involving cinema. The article promotes scientific research based on understanding of the works dedicated to the dialogue between teaching of History and cinema published in Proceedings of the Brazilian National Meeting of Researchers of History Teaching (ENPEH), from 1995 to 2013. The aim of the study is to understand the characteristics of this field/social place of research through an analysis of the authors, based on their Lattes curriculum (on-line Brazilian re-
\end{abstract}

\footnotetext{
* Universidade Estadual Paulista “Júlio de Mesquita Filho" (Unesp), São José do Rio Preto, SP, Brasil. perinellineto@yahoo.com.br

** Universidade Estadual Paulista "Júlio de Mesquita Filho" (Unesp), São José do Rio Preto, SP, Brasil.mah.brandolezi@gmail.com

*** Universidade Estadual Paulista "Júlio de Mesquita Filho" (Unesp), São José do Rio Preto, SP, Brasil. ricardo.scucuglia@unesp.br

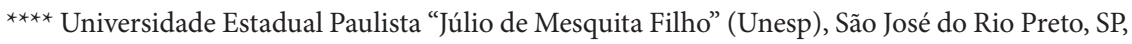
Brasil.edilson.oliveira@unesp.br
} 
A pesquisa apresenta abordagem qualitativa e natureza aplicada e concilia descrição e explicação, investigações bibliográficas e documentais.

Palavras-chave: ensino de história; cinema; ENPEH. searchers' CVs). The research presents a qualitative approach, applied nature and it integrates description and explanation, using bibliographical and documentary investigations.

Keywords: history teaching; cinema; ENPEH.

Em 1988, Elza Nadai organizou o evento Perspectivas do Ensino de História. O Encontro Nacional de Pesquisadores do Ensino de História (ENPEH) foi criado posteriormente (Siman; Ricci, 2006; Mesquita, 2011), de modo que, entre 1993 e 2013, foram organizadas dez edições do ENPEH em Universidades de diferentes estados brasileiros (Quadro 1).

Quadro 1 - Edições do ENPEH, 1993/2013

\begin{tabular}{|c|l|l|}
\hline Ano & \multicolumn{1}{|c|}{ Cidade } & \multicolumn{1}{|c|}{ IES } \\
\hline 1993 & Uberlândia, MG & Universidade Federal de Uberlândia (UFU) \\
1995 & Niterói, RJ & Universidade Federal Fluminense (UFF) \\
1997 & Campinas, SP & Universidade de Campinas (Unicamp) \\
1999 & Ijuí, RS & Universidade Regional do Noroeste do \\
2001 & João Pessoa, PB & Rio Grande do Sul (Unijuí) \\
2003 & Londrinarsidade Federal da Paraíba (UFP) & Universidade Estadual de Londrina (UEL) \\
2006 & Belo Horizonte, MG & Universidade Federal de Minas Gerais (UFMG) \\
2008 & São Paulo, SP & Universidade de São Paulo (USP) \\
2011 & Florianópolis, SC & Universidade Federal de Santa Catarina (UFSC) \\
2013 & Aracaju, SE & Universidade Federal do Sergipe (UFS) \\
\hline
\end{tabular}

Fonte: Tabulação pelo autor.

O ENPEH objetivava contemplar novas demandas surgidas após excesso de controle governamental vivido durante a ditadura militar. Novas questões estavam postas e caminhos foram surgindo para o ensino de História. As várias edições desse evento indicam, sobretudo, o crescimento do campo e o amadurecimento das pesquisas na área. 
O objetivo do evento foi e é o de possibilitar a troca de experiências entre os pesquisadores que investigam o ensino de História, além de ampliar a aprofundar problemáticas referentes a: temas, procedimentos metodológicos, fontes de pesquisa e referenciais teórico-metodológicos presentes no campo do ensino de História.

O ENPEH permite o encontro e o diálogo entre professores das áreas pedagógicas e específicas de História, proporcionando visão mais ampla do que está sendo pesquisado e discutido no campo do ensino de História, integrando saberes a partir da troca de experiências e contribuindo com a formação permanente de professores e de pesquisadores.

O objetivo deste trabalho é analisar os trabalhos envolvendo cinema e ensino de História apresentados no ENPEH entre 1995 e 2013, tomando como base os conceitos de campo, lugar social e indícios, conforme definidos, respectivamente, por autores como Pierre Bourdieu (2004; 2011), Michel de Certeau (1982) e Carlo Ginzburg (1989; 2007a; 2007b).

Bourdieu define campo como

rede ou uma configuração de relações objetivas entre posições. Essas posições são definidas objetivamente em sua existência e nas determinações que elas impõem aos seus ocupantes, agentes ou instituições, por sua situação (situs) atual e potencial na estrutura da distribuição das diferentes espécies de poder (ou de capital) cuja posse comanda o acesso aos lucros específicos que estão em jogo no campo e ao mesmo tempo, por suas relações objetivas com outras posições (dominação, subordinação, homologia etc.). (Bourdieu, 2011, p. 72)

Com base na noção de campo, Bourdieu faz intensa crítica sobre as instituições universitárias e acadêmicas, revelando ser impossível a neutralidade do conhecimento científico. $\mathrm{O}$ autor insiste em debater os interesses e os valores que envolvem a produção científica, revelando as relações de poder e de dominação existentes no campo da ciência. Tais relações implicam a apropriação dos meios de produção e de dominação, ou mais precisamente, o capital científico, cuja fonte de legitimação seriam os intelectuais/cientistas abrigados nas instituições.

As reflexões de Pierre Bourdieu dialogam com a noção de lugar social apresentada por Michel de Certeau, para ressaltar a criação e a reprodução das disputas de poder pela legitimação científica, social e política das investigações entre os historiadores. Conforme o próprio Michel de Certeau: 
Encarar a história como uma operação será tentar, de maneira necessariamente limitada, compreendê-la como a relação entre um lugar (um recrutamento, um meio, uma profissão etc.), procedimentos de análise (uma disciplina) e a construção de um texto (uma literatura). É admitir que ela faz parte da "realidade" da qual trata, e que essa realidade pode ser apropriada "enquanto atividade humana", "enquanto prática". Nesta perspectiva, gostaria de mostrar que a operação histórica se refere à combinação de um lugar social, de práticas "científicas" e de uma escrita. Essa análise das premissas, das quais o discurso não fala, permitirá dar contornos precisos às leis silenciosas que organizam o espaço produzido como texto. A escrita histórica se constrói em função de uma instituição cuja organização parece inverter: com efeito, obedece a regras próprias que exigem ser examinadas por elas mesmas. (Certeau, 1982, p. 56, grifos no original)

O discurso do historiador se alicerça num sistema de regras, que pode ser até implícito dentro da Instituição, mas influencia, enfim: o que pode ou não ser estudado (objetos e temas) e como pode ser estudado (materiais, metodologias e teorias). Assim sendo, a validade do discurso do historiador depende da aprovação de seus pares, pois "não existe relato histórico no qual não esteja explicitada a relação com um corpo social e com uma instituição de saber" (Certeau, 1982, p. 88). Para esse autor

Existem as leis do meio. Elas circunscrevem possibilidades cujo conteúdo varia, mas cujas imposições permanecem as mesmas. Elas organizam uma "polícia" do trabalho. Não "recebido" pelo grupo, o livro cairá na categoria de "vulgarização" que, considerada com maior ou menor simpatia, não poderia definir um estudo como "historiográfico". Ser-lhe-á necessário o ser "acreditado" para aceder à enunciação historiográfica. $\mathrm{O}$ estatuto dos indivíduos que têm - e somente eles - o direito regulamentar ou tradicional, juridicamente definido ou espontaneamente aceito, de proferir um discurso semelhante depende de uma "agregação" que classifica o "eu" do escritor no "nós" de um trabalho coletivo, ou que habilita um locutor a falar o discurso historiográfico. Este discurso - e o grupo que o produz - faz o historiador, mesmo que a ideologia atomista de uma profissão "liberal" mantenha a ficção do sujeito autor e deixe acreditar que a pesquisa individual constrói a história. (Certeau, 1982, p. 63)

A tarefa de operar com os conceitos de campo, capital científico e lugar social pode ser realizada com base no paradigma indiciário, conforme 
definição traçada por Carlo Ginzburg. Isso porque "a realidade é opaca, existem zonas privilegiadas - sinais, indícios - que permitem decifrá-la [...] o que caracteriza esse saber é a capacidade, a partir de dados aparentemente negligenciáveis, de remontar a realidade complexa não experimentável diretamente" (Ginzburg, 1989, p.152 e 177).

Utilizar o paradigma indiciário implica observar detalhes do fato investigado e não apenas o que se mostra evidente. Trata-se de examinar os pormenores, aspectos negligenciáveis e indícios imperceptíveis. Essa abordagem permite remontar uma realidade complexa, que não é diretamente experimentável. Partir do estudo intensivo de indícios e de detalhes revela problemas de ordem mais geral.

O paradigma indiciário envolve diretamente o surgimento da micro-história, já que essa historiografia apontou para a identificação dos sujeitos envolvidos nos acontecimentos históricos a serem reconstituídos. Foi com essa preocupação que Ginzburg propôs, entre outras formas, investigações que tomem o nome como fio condutor da investigação. Para ele o "fio de Ariadne que guia o investigador no labirinto documental é aquilo que distingue um indivíduo de um outro em todas as sociedades conhecidas: o nome" (Ginzburg, 1989, p. 174).

Com base nesses autores é que desenvolvemos pesquisa cuja abordagem é qualitativa, natureza aplicada e que concilia descrição e explicação, valendo-se para isso de investigações bibliográficas e documentais (Gil, 1994; 2007; Minayo, 2000; Triviños, 1987; Gamboa, 1997; Alves-Mazzotti; Gewandsznajder, 1999; André; Ludke, 2005).

As investigações são bibliográficas e documentais, tendo em vista que baseadas em três conjuntos de materiais: 1) artigos, livros e capítulos de livros relacionados a cinema e ensino de História, principalmente; o 2) currículos Lattes de pesquisadores identificados no ENPEH; e 3) textos completos publicados nos Anais do ENPEH 1995/2013.

Existem obras que promoveram reflexões sobre o cinema, tendo como foco as possibilidades epistemológicas contidas num filme (Rancière, 2013; 2012; 2005; Cabrera, 2006; Morin, 1997; Pourriol, 2009; Sorlin, 1994; 1985), inclusive para a construção do conhecimento histórico (Ferro, 2010; Rosenstone, 2010; Nóvoa; Barros, 2008; Nóvoa; Fressato; Feigelson, 2009).

Verificou-se também a existência de reflexões envolvendo cinema e ensino, mas dedicando esforços a pensar nas estratégias a serem empregadas pelo docente, ao lançar mão de filmes para discussão (Napolitano, 2008; Kenski, 1996; Falcão; Bruzzo, 1993). 
Há ainda estudos cujo propósito foi o de compreender o desenvolvimento do cinema educativo no Brasil entre 1920 e 1950, experiência que, em boa medida, associou o emprego dos filmes a objetivos moralizantes, controle ideológico, bem como ufanismo e heroificação (Monteiro, 2006; Catelli, 2007; Saliba, 2003).

Encontram-se também estudos a respeito de cinema e educação, tendo como foco a importância da escola para alfabetização do olhar, acesso e popularização de filmes, formação docente e construção de ensino/aprendizagem crítico (Duarte, 2002; Setton, 2004; 2010; Fischer, 2009; Marcello, 2010; Fantin, 2006; Belloni; Bévort, 2009; Fresquet, 2013).

Por fim, identificou-se outra abordagem, voltada a incentivar o emprego do cinema nas práticas educativas de História, bem como refletir sobre as dificuldades em torno disso (Bittencourt, 2006; 2008; Fonseca, 2009; Silva; Fonseca, 2007; Silva; Ramos, 2011; Araújo Filho, 2007; Nascimento, 2008; Capelato, 2007).

Embora tenham surgido estudos envolvendo filmes e ensino de História há certo tempo e o emprego dessas obras na escola não seja novidade, ressente-se de reflexões dedicadas ao entendimento do cinema como objeto de pesquisa dos estudiosos do ensino de História.

Entende-se por cinema uma tecnologia audiovisual criada em fins do século XIX, fruto dos avanços científico e da constituição da indústria do entretenimento (Crary, 1995; Barbosa Júnior, 2002), que marca a constituição da visão desterritorializada (Aumont, 2004; Rancière, 2012; Schwartz; Charney, 2001) e que envolve nova forma de produção do conhecimento, tida como "logopática” (Cabrera, 2006), "razão poética" (Nóvoa; Fressato; Feigelson, 2009) ou associada à "partilha do sensível” (Rancière, 2005).

Este estudo foi promovido por autores envolvidos num grupo interdisciplinar de pesquisa, situado na área do Ensino, e em reconhecimento: 1) da importância nos últimos tempos das TIC no desenvolvimento de práticas educativas, aí inclusas aquelas que envolvem o cinema; e 2) da importância de perscrutar os Anais do Encontro Nacional de Pesquisadores do Ensino de História (ENPEH), dado que é o evento mais representativo nesse campo.

\section{PESQUisas E TRAJETÓRIAS}

O Gráfico 1 permite notar que ao longo dos anos o ENPEH foi crescendo. Contudo, o número de trabalhos envolvendo cinema e ensino de História 
manteve-se na mesma média, entre dois e quatro, tendo seu ápice nas edições realizadas em 2003 e 2006, quando se registrou a publicação de quatro trabalhos, assim como em 2013, ocasião em que constaram cinco trabalhos.

Gráfico 1 - Trabalhos sobre Cinema

e Ensino de História no ENPEH (1995/2013)

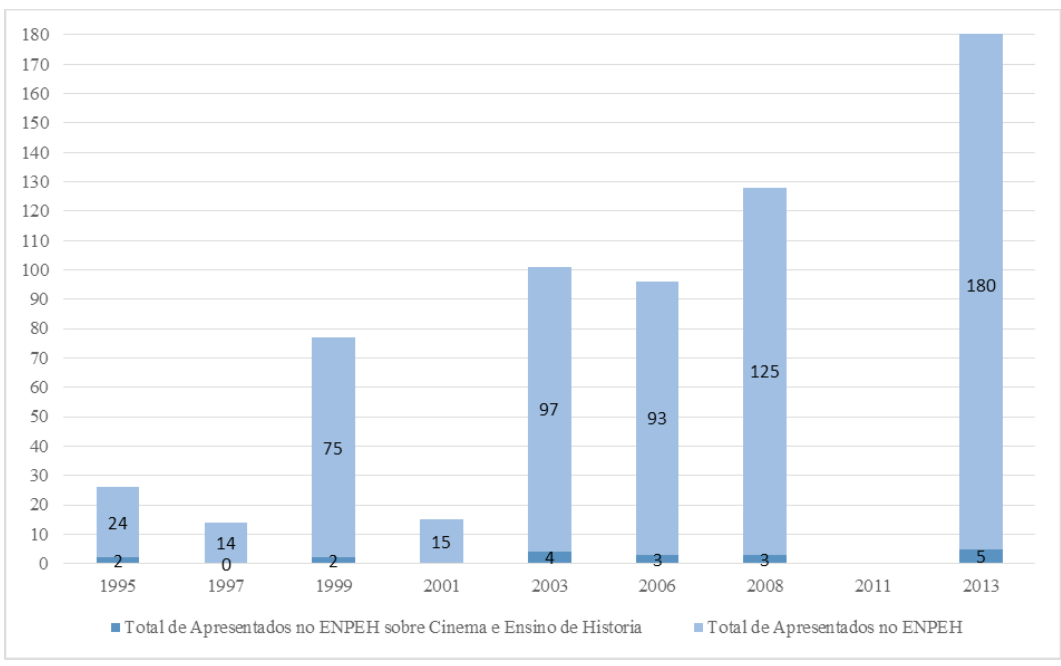

Fonte: Anais do Encontro Nacional dos Pesquisadores do Ensino de História (1995/2013).

Nesse Gráfico não constam os textos que compuseram os Anais da edição 2011 do ENPEH. Ao que tudo indica, esses textos têm seu acesso dificultado pelo fato de serem os primeiros publicados em páginas virtuais postadas na internet e não mais em mídia física, como CDs, num momento em que tais páginas ainda não eram totalmente seguras. Todas as buscas na internet se mostraram ineficazes. De qualquer modo, dado que se trata apenas de uma edição (em relação ao conjunto formado por nove edições), entende-se que os dados ausentes não alteram, de modo significativo, a compreensão do panorama da produção de trabalhos no campo de "cinema e ensino de História".

Esse campo de estudo está consolidado, vez que é possível encontrar trabalhos dessa natureza em praticamente todas as edições perscrutadas. Entretanto, parece limitado em certa média, não crescendo nem diminuindo significativamente o número de produções. 
Dado importante a se considerar é o fato de que, em 2001, houve a participação do pesquisador francês Marc Ferro, renomado pesquisador na área de cinema e História. Como houve aumento do número de trabalhos publicados na edição posterior do ENPEH (2003), pode-se inferir que, na companhia de outros fatores, a presença de Ferro colaborou para tanto ou sinalizou mudança ocorrida nesse campo, por volta do início do novo século.

Quadro 2 - Autores que publicaram sobre Ensino de História e Cinema nas edições do ENPEH, 1993/2013

\begin{tabular}{|c|l|}
\hline Ano & \multicolumn{1}{|c|}{ Autores } \\
\hline 1993 & - \\
\hline 1995 & Bittencourt; Soares \\
\hline 1997 & - \\
\hline 1999 & Silva; Gerhardt \\
\hline 2001 & - \\
\hline 2003 & Duarte; Ferreira; Gomes; Melo Silva; Molina \\
\hline 2006 & Abdala Junior; Dantas; Costa; Rangel; Frazzi; Fortes; Meirelles \\
\hline 2008 & Melo Silva; Meirelles; Luiz Júnior; Teruya \\
\hline 2011 & - \\
\hline 2013 & Oliveira; Moura da Silva; Santos; Lima; Ribeiro dos Santos; Trovão \\
\hline
\end{tabular}

Fonte: Anais do ENPEH (1995/2013).

É possível notar (Quadro 2) que 24 autores de textos envolvendo cinema e ensino de História compareceram nas edições do ENPEH realizadas entre 1993 e 2013. Desse conjunto, apenas dois participaram/publicaram em mais de uma edição: Meirelles (2006; 2008) e Melo Silva (2003; 2008).

Quadro 3 - Projetos de Pesquisa Cinema e Ensino de História: Meirelles

\begin{tabular}{|l|c|c|}
\hline \multicolumn{1}{|c|}{ Título do projeto } & Início & Fim \\
\hline Imagens do Brasil: relações entre cidade e campo nos filmes & 2003 & Atual \\
\hline Cinema e História: o uso do filme como recurso didático & 2003 & Atual \\
\hline
\end{tabular}

Fonte: Currículo Lattes: Meirelles. http://lattes.cnpq.br/5228822691259333.

Acesso em: 4 jan. 2019. 
Quadro 4 - Projetos de Pesquisa Cinema e Ensino de História: Abdala Junior

\begin{tabular}{|l|l|l|}
\hline \multicolumn{1}{|c|}{ Título do projeto } & Início & Fim \\
\hline A história no cinema brasileiro da segunda metade do século XX & 2003 & Atual \\
\hline $\begin{array}{l}\text { Grupo de Estudos e Pesquisa em História, Cinema e Audiovisual } \\
\text { - GEP-HIS }\end{array}$ & 2003 & Atual \\
\hline Cineclube História na tela: imagens do Brasil & 2003 & Atual \\
\hline $\begin{array}{l}\text { Didática da História: performances culturais das narrativas } \\
\text { audiovisuais na construção do conhecimento sobre o passado }\end{array}$ & 2013 & Atual \\
\hline
\end{tabular}

Fonte: Currículo Lattes: Addalla Junior. http://lattes.cnpq.br/7014946989727038.

Acesso em: 4 jan. 2019.

Quadro 5 - Projetos de Pesquisa Cinema e

Ensino de História: Ribeiro dos Santos

\begin{tabular}{|l|c|c|}
\hline \multicolumn{1}{|c|}{ Título do projeto } & Início & Fim \\
\hline $\begin{array}{l}\text { Sala de aula, sala de projeção: a relação cinema e ensino de } \\
\text { História: Estudo de caso na cidade de Rondonópolis, MT }\end{array}$ & 2013 & 2015 \\
\hline
\end{tabular}

Fonte: Currículo Lattes: Ribeiros dos Santos. http://lattes.cnpq.br/7014946989727038. Acesso em: 4 jan. 2019.

Quadro 6 - Projetos de Pesquisa Cinema e Ensino de História: Trovão

\begin{tabular}{|l|c|c|}
\hline \multicolumn{1}{|c|}{ Título do projeto } & Início & Fim \\
\hline $\begin{array}{l}\text { Curtindo com a escola adoidado: cinema, educação e política } \\
\text { nos Estados Unidos dos anos 1980 }\end{array}$ & 2017 & Atual \\
\hline $\begin{array}{l}\text { Sala de aula, sala de projeção: a relação cinema e ensino de } \\
\text { História. Estudo de caso na cidade de Rondonópolis }\end{array}$ & 2013 & 2015 \\
\hline
\end{tabular}

Fonte: Currículo Lattes: Trovão. http://lattes.cnpq.br/7014946989727038.

Acesso em: 4 jan. 2019.

Igualmente com base no currículo Lattes, verificamos o envolvimento ou não desses 24 autores, entre 1993 e 2013, com projetos de pesquisa que versam sobre a relação entre cinema e ensino de História. Notou-se, então, que apenas 
quatro autores desenvolvem projetos a esse respeito: Meirelles, Abdala Junior, Ribeiro dos Santos e Trovão (Quadros 3, 4, 5 e 6).

Do grupo de 24 autores que participaram/publicaram textos em edições do ENPEH, apenas nove possuem número relevante de produções bibliográficas sobre o tema "cinema e ensino de História": Melo Silva (2006; 2008), Meirelles (2006; 2008), Abdala Junior (2006), Luiz Junior (2008), Teruya (2008), Oliveira (2013), Santos (2013), Ribeiro dos Santos (2013) e Trovão (2013).

Mesmo quem produziu volume significativo de trabalhos nesse campo merece observações. Santos (2013), por exemplo, apresenta publicações, mas seus textos envolvem mais a relação entre cinema e televisão. Isso também acontece com Lima (2013), que apresenta cinco publicações nesse campo, embora tenha produzido número maior de trabalhos em outros temas, como a influência da televisão nos alunos e o meio ambiente.

$\mathrm{O}$ fato de a maioria dos autores não ter publicado em mais de um evento pode ser indício de que as pesquisas sobre cinema e ensino de História não são consistentes. Além disso, analisando os projetos de pesquisas nos quais esses autores se envolveram, percebe-se que apenas dois deles desenvolvem projetos associados a cinema e ensino de História, portanto, é possível considerar que os trabalhos apresentados nas edições do ENPEH parecem episódicos. Tais pesquisas podem estar associadas, na verdade, às experiências em sala de aula ou que derivam de reflexões secundárias de pesquisas envolvendo outro tema.

Dentre os textos apresentados, cabe ressaltar que quatro foram produzidos por mais de um autor: Ferreira e Gomes publicaram juntas em 2003; Dantas, Costa, Rangel, Frazi e Fortes, em 2006; Luiz Junior e Teruya em 2008, e Ribeiro dos Santos e Trovão em 2013. Os 19 textos restantes derivam de reflexões individuais: Bittencourt (1995), Soares (1995), Silva (1999), Gerhardt (1999), Duarte (2003), Molina (2003), Melo Silva (2003 e 2008), Abdala Junior (2006), Meirelles (2006 e 2008), Oliveira (2013), Moura da Silva (2013), Santos (2013) e Lima (2013).

Um dado interessante pode ser depreendido desse quadro. O número de trabalhos envolvendo reflexões individuais sobressai aos trabalhos publicados de forma coletiva (19 em relação a quatro textos), o que também pode indicar pouca força do tema nas pesquisas, uma vez que, via de regra, projetos de fôlego são desenvolvidos por vários pesquisadores, especialmente em grupos de pesquisa formalmente instituídos e com projetos coletivos. A individualidade 
na autoria pode reforçar a hipótese de experiências em sala de aula ou que derivam de reflexões secundárias de pesquisas envolvendo outro tema.

\section{Gráfico 2 - Publicações dos autores ENPEH (1995/2013): artigos, livros e capítulos de livros}

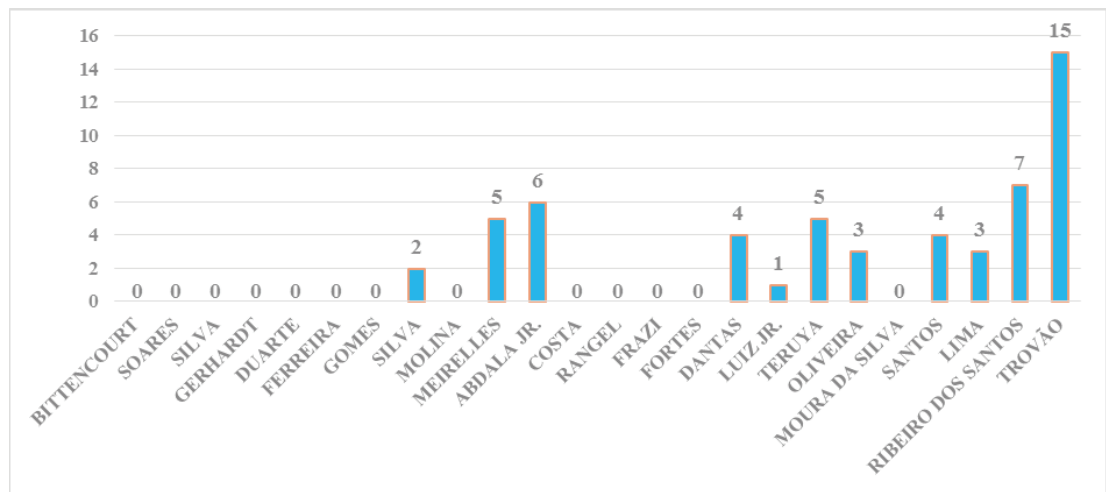

Fonte: Currículos Lattes dos autores pesquisados em http://lattes.cnpq.br/. Último acesso em: 4 jan. 2019.

Prosseguindo na análise dos currículos Lattes é possível verificar que dez dos 24 autores publicaram apenas um trabalho sobre cinema e ensino de História, ao longo de sua carreira (40\% do grupo). Tal publicação isolada, aliás, ocorreu, justamente, numa das edições do ENPEH, realizadas entre 1995 e 2013: Gerhardt (1999), Duarte (2003), Ferreira (2003), Gomes (2003), Costa (2006), Dantas (2006), Rangel (2006), Frazi (2006), Fortes (2006) e Moura da Silva (2013). Comumente, pesquisas de fôlego requerem certo tempo de trabalho e volume de publicação sobre o mesmo tema, o que não parece ser o caso.

É ainda interessante notar, analisando o currículo dos pesquisadores, que aqueles que continuaram estudando o tema "cinema e ensino de História" publicaram em outros eventos acadêmico-científicos, boa parte com abrangência local e regional (caso de Semanas da Pedagogia), a maioria absoluta não dedicada ao tema (como o Ciclo da História Medieval) e apenas alguns voltados a discutir a relação entre novas tecnologias e História, por exemplo (Simpósio Nacional de História e Encontro Internacional do Ensino de História).

Prosseguindo na análise dos currículos Lattes, percebe-se que outros nove autores $(37,5 \%)$ apenas passaram pontualmente pela abordagem de "cinema e 
ensino de História", uma vez que seus esforços estão voltados para outros temas de pesquisa, próximos ou distantes dos debates envolvendo filmes, a saber: livro didático (Bittencourt), escravidão/África (Soares), História ambiental (Gerhardt), política educacional (Melo Silva), música e fotografia (Duarte) ou imagens na História (Molina), bem como currículos no ensino de História (Costa), televisão (Santos) e meio ambiente (Lima).

Do grupo de 24 autores que participaram/publicaram textos em edições do ENPEH, apenas nove apresentam número relevante de produções bibliográficas sobre o tema "cinema e ensino de História". Analisando os eventos em que esses trabalhos foram apresentados, dificilmente se encontra mais de uma publicação em edições diferentes. Também foi possível perceber que alguns desses autores apenas passaram pontualmente pela abordagem do tema "cinema e ensino de História”, uma vez que apenas quatro deles se envolveram com projetos de pesquisa nesse sentido.

Tendo em vista todos esses dados, pode-se argumentar que as pesquisas em cinema e ensino de História não constituem campo de estudos consagrado. Nas relações de poder e de dominação existentes, tal campo parece não desfrutar de capital científico expressivo (Bourdieu, 2004; 2011). Daí as poucas publicações no ENPEH, o número pequeno de publicações sobre o tema no conjunto de trabalhos dos autores analisados, a predominância de iniciativas individuais sobre as coletivas, assim como a ausência de participação desses autores em eventos mais específicos (voltados ao cinema e ensino de História). Enfim, os intelectuais e cientistas abrigados nas universidades não parecem legitimar esse campo.

A situação tende a constituir cenário curioso. O cinema continua a ser apresentado como material didático inovador em sala de aula, mesmo tendo sido inventado há mais de 120 anos e de ser empregado nas escolas há pelo menos um século. Entende-se que isso se deva, justamente, embora não de modo exclusivo, ao fato de não se ter constituído em objeto de pesquisa, de fato e de modo longitudinal, nos campos da Educação e do Ensino. Apropriar-se dele, de modo que sejam construídas epistemologias e metodologias que o tomem como linguagem específica, é tarefa a ser construída, quando se pretende utilizá-lo para construção de práticas pedagógicas. 


\section{FORMAÇÕES E INSTITUIÇÕES}

A graduação constitui-se em espaço para a iniciação científica, portanto, momento em que o pesquisador começa a se formar, sendo o mestrado espaço de aperfeiçoamento dessa formação e de habilitação para o Ensino Superior, enquanto o doutorado perfaz ocasião dedicada à consolidação do pesquisador. Chama atenção o fato de as pesquisas envolvendo cinema e ensino de História decrescerem entre os graduados, mestres e doutores.

Gráfico 3 - Formação dos autores ENPEH (1995/2013):

Graduação, Mestrado e Doutorado

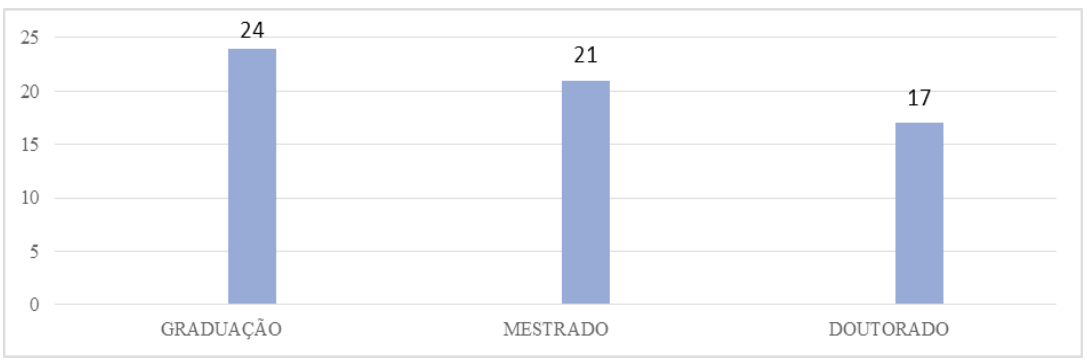

Fonte: Currículos Lattes dos autores pesquisados em http://lattes.cnpq.br/. Último acesso em: 4 jan. 2019.

Observa-se (Gráfico 3) que a dedicação ao tema "cinema e ensino de História” diminuiu entre a graduação e o doutorado. Esses números permitem entender que, embora se mantenha como objeto de pesquisa na Pós-Graduação, o tema está mais presente entre os professores em formação ou como objeto abordado em sala de aula por professores.

Gráfico 4 - Formação dos autores ENPEH (1995/2013): Cursos de Graduação

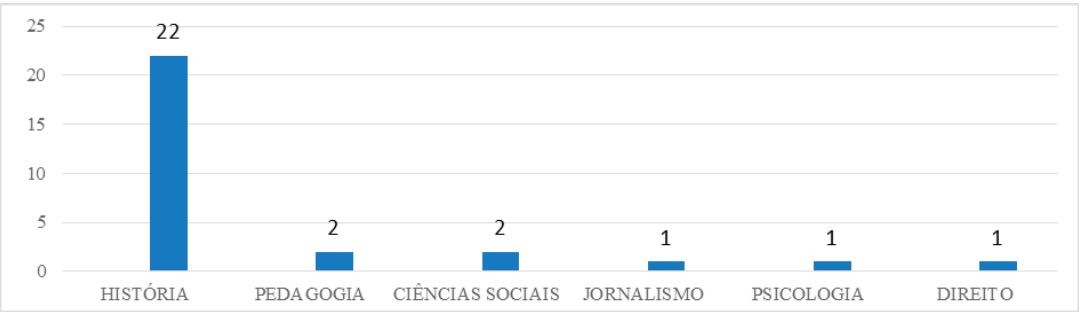

Fonte: Currículos Lattes dos autores pesquisados em http://lattes.cnpq.br/. Último acesso em: 4 jan. 2019. 
No que se refere à graduação dos 24 autores analisados (Gráfico 4), a maioria (22, ou seja, 89\%) cursou História: Bittencourt, Soares, Silva, Gerhardt, Duarte, Ferreira, Gomes, Melo Silva, Molina, Meirelles, Abdala Junior, Costa, Rangel, Dantas, Luiz Junior, Teruya, Oliveira, Moura da Silva, Santos, Lima, Ribeiro dos Santos e Trovão. Apesar de ser graduação majoritariamente voltada para a formação de professores, verifica-se que o currículo e as práticas constituintes da graduação em História estiveram marcados pela preocupação conteudista, reprodutora do “esquema 3+1" e responsável por menorizar reflexões sobre as metodologias de ensino, caso do emprego do cinema no ensino de História (Bittencourt, 2008; Fonseca, 2003) Esse problema estrutural da formação de professores (não apenas os de História) foi resumido por Saviani:

Tudo indica que na raiz desse dilema está a dissociação entre os dois aspectos indissociáveis da função docente: a forma e o conteúdo. Considerando o modo como estão constituídas as especializações universitárias, dir-se-ia que os estudantes, que vivenciaram na educação básica a unidade dos dois aspectos, ao ingressar no ensino superior terão adquirido o direito de se fixar apenas em um deles. Em consequência, os que foram aprovados no vestibular de Pedagogia não precisam mais se preocupar com os conteúdos. E os que foram aprovados nos vestibulares das diferentes disciplinas de licenciatura se concentram apenas nos respectivos conteúdos específicos, despreocupando-se com as formas a eles correspondentes. (Saviani, 2009, p. 151)

Outras seis (25\%) graduações foram cursadas, como primeira ou segunda experiência. Dois autores cursaram Pedagogia: Frazi e Fortes; um cursou Jornalismo: Melo Silva; dois cursaram Ciências Sociais (e História): Duarte e Teruya; um cursou Jornalismo (e História): Melo Silva; um cursou Psicologia e Direito: Lima; registra-se, por fim, um autor que cursou Teologia (e História): Santos.

O Gráfico 5 apresenta as Instituições de Ensino Superior (IES) onde os autores cursaram graduação (alguns deles, mais de uma). Verifica-se destaque para a Universidade Federal de Santa Catarina (UFSC: Costa, Frazi, Fortes e Dantas - 16\%) e a Universidade de São Paulo (USP: Bittencourt, Duarte, Melo Silva e Gomes - 16\%). Em seguida, a Pontifícia Universidade Católica (PUC: Ferreira, Soares e Santos - 12,5\%), as Faculdades Auxilium de Lins (Teruya e Molina - 8\%), bem como a Universidade Estadual Paulista "Júlio de Mesquita 
Gráfico 5 - IES em que autores ENPEH (1995/2013) cursaram a graduação

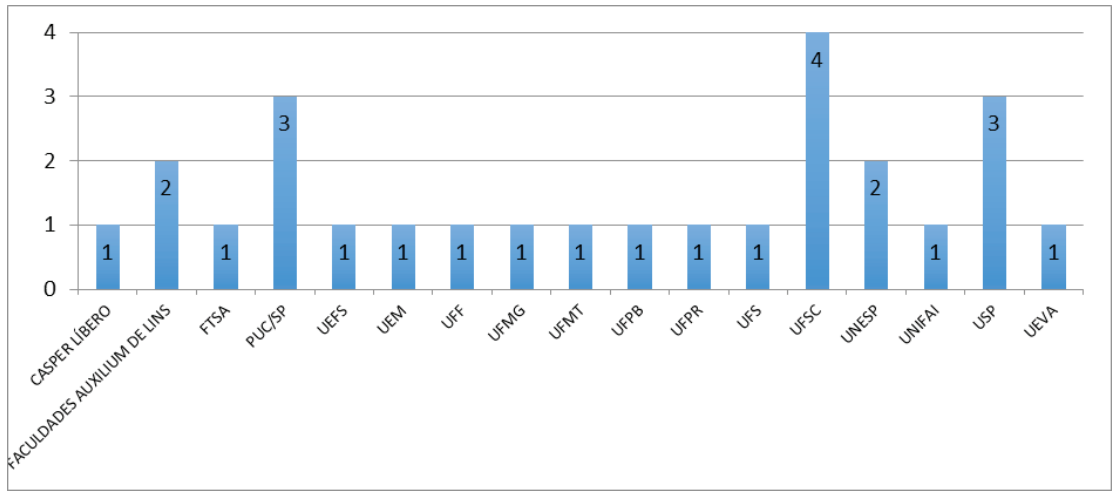

Fonte: Currículos Lattes dos autores pesquisados em http://lattes.cnpq.br/. Último acesso em: 4 jan. 2019.

Filho", a Unesp (Meirelles e Teruya - 8\%). Juntas, as cinco IES formaram cerca de $60 \%$ dos graduados em questão.

Ainda em relação ao Gráfico 5, 13 IES contam com um autor cada (somando aproximadamente 40\%): Faculdade Teleológica Sul Americana (FTSA: Santos), Faculdades Associadas do Ipiranga (FAI: Duarte), Universidade Estadual de Feira de Santana (UEFS: Silva), Universidade Estadual de Maringá (UEM: Luiz Junior), Universidade Federal de Minas Gerais (UFMG: Abdala Junior), Universidade Federal Fluminense (UFF: Rangel), Universidade Federal de Mato Grosso (UFMT: Ribeiro dos Santos), Universidade Federal da Paraíba (UFPB: Moura da Silva), Universidade Federal do Paraná (UFPR: Trovão), Universidade Federal de Sergipe (UFS: Lima), Universidade Federal do Pará (UFPA: Ferreira), Universidade Regional do Noroeste do Estado do Rio Grande do Sul (Unijuí: Gerhardt), Universidade Estadual do Vale do Acaraú (Ueva: Oliveira), Faculdade Cásper Líbero (FCL: Melo Silva) e Universidade Católica de Goiás (UCG: Santos).

O Gráfico 6 apresenta os cursos de mestrado frequentados pelos autores de textos sobre cinema e ensino de História publicados nas edições do ENPEH entre 1995 e 2013. Destaca-se o grupo de mestres no campo da História (considerando-se formações como História, História Social, Memória Social e Metodologia e Teoria da História), com oito autores: Duarte, Meirelles, Bitencourt, Gerhardt, Ferreira, Oliveira, Santos e Trovão (Quadro 7). 
Gráfico 6 - Formação dos autores ENPEH (1995/2013):

Cursos de Mestrado

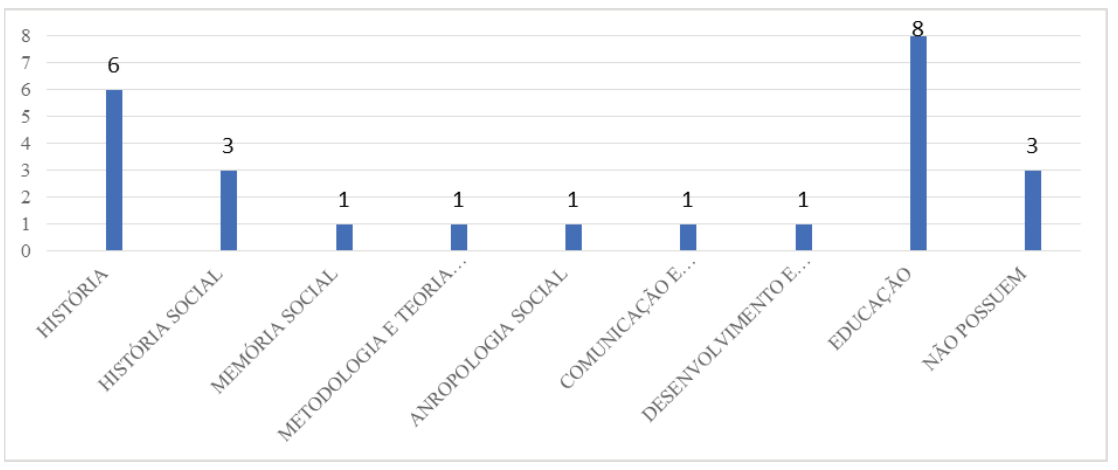

Fonte: Currículos Lattes dos autores pesquisados em http://lattes.cnpq.br/. Último acesso em: 4 jan. 2019.

$$
\begin{gathered}
\text { Quadro } 7 \text { - Autores ENPEH (1995/2013) que cursaram } \\
\text { Mestrado no campo da História }
\end{gathered}
$$

\begin{tabular}{|l|l|}
\hline \multicolumn{1}{|c|}{ Autor } & \multicolumn{1}{c|}{ Título da Dissertação } \\
\hline Duarte & Rumo ao Campo - a civilização pela escola \\
\hline Meirelles & Cinema e História: O Cinema Brasileiro nos anos 50 \\
\hline Bitencourt & $\begin{array}{l}\text { Pátria, Civilização e Trabalho: Ensino de História nas Escolas } \\
\text { Paulistas (1917-1939) }\end{array}$ \\
\hline Gerhardt & $\begin{array}{l}\text { Estado, estancieiros, caboclos e colonos modificam o ambiente: a } \\
\text { História da Colônia Ijuhy }\end{array}$ \\
\hline Ferreira & $\begin{array}{l}\text { Em tempo cabanal: cidade e mulheres no Pará imperial - primeira } \\
\text { metade do século XIX }\end{array}$ \\
\hline Oliveira & $\begin{array}{l}\text { Da arte de curar à prisão de um ocultista: ocultismo, magia e ciência } \\
\text { em Aracaju, SE (1923-1928) }\end{array}$ \\
\hline Santos & O sonho de uma geração (CENOG e movimento separatista) 1959-1968 \\
\hline Trovão & Homens de ciência: a medicina legal no Brasil da Belle Époque \\
\hline
\end{tabular}

Fonte: Currículos Lattes dos autores pesquisados em http://lattes.cnpq.br/. Último acesso em: 4 jan. 2019.

Constam ainda outros 11 que cursaram mestrado. Desse conjunto, sobressaem oito cuja formação envolveu programas de Pós-Graduação em 
Educação: Molina, Melo Silva, Abdala Junior, Costa, Dantas, Luiz Junior, Teruya e Ribeiro dos Santos. Os outros três cursaram em áreas diferentes: Comunicação e Cultura Contemporânea, Antropologia Social e Meio Ambiente.

Quadro 8 - Autores ENPEH (1995/2013) que cursaram Mestrado em Educação

\begin{tabular}{|c|c|}
\hline Autor & Título da dissertação \\
\hline Molina & A formação de professores de História \\
\hline Melo Silva & Ensino de História, Cinema, Imprensa e Poder na Era Vargas \\
\hline Abdala Junior & História e cinema: um diálogo educativo \\
\hline Costa & $\begin{array}{l}\text { A década de } 1980 \text { e os embates curriculares: a proposta para o } \\
\text { ensino de História em Florianópolis }\end{array}$ \\
\hline Dantas & $\begin{array}{l}\text { Competências e Habilidades na Formação dos Professores das } \\
\text { Séries Iniciais de Nível Médio em Santa Catarina: uma análise } \\
\text { no contexto das Leis 5.692/71 e 9.394/96 }\end{array}$ \\
\hline Luiz Junior & $\begin{array}{l}\text { O Cinema como Fonte de Pesquisa Na Sala de Aula: Análise } \\
\text { Fílmica Sobre a Resistência Armada à Ditadura Militar } \\
\text { Brasileira }\end{array}$ \\
\hline Teruya & Um estudo sobre a representação da escola numa classe de 5 a. série \\
\hline $\begin{array}{l}\text { Ribeiro dos } \\
\text { Santos }\end{array}$ & $\begin{array}{l}\text { "Juventude em Fúria": Representações, tensões e política no } \\
\text { governo Reagan }\end{array}$ \\
\hline
\end{tabular}

Fonte: Currículos Lattes dos autores pesquisados em http://lattes.cnpq.br/. Último acesso em: 4 jan. 2019.

O Quadro 8 permite entender o currículo Lattes dos oito autores que cursaram mestrado em Educação. Nota-se que apenas três deles (Melo Silva, Abdala Junior e Luiz Júnior) desenvolveram temas envolvendo cinema e ensino de História. Assim, a maioria (cinco autores) não se dedicou ao tema em sua formação no nível de mestrado (Molina, Costa, Dantas, Teruya e Ribeiro dos Santos).

No nível de mestrado, os autores estão agrupados em apenas 15 IES, número menor do que as 18 identificadas no nível de graduação (Gráfico 7). Sabendo-se que no Brasil existem 296 Universidades Públicas (Inep, 2017), ressalta-se a concentração regional: seis situam-se no Sudeste e quatro no Sul. 
Gráfico 7 - IES em que autores ENPEH (1995/2013) cursaram o Mestrado

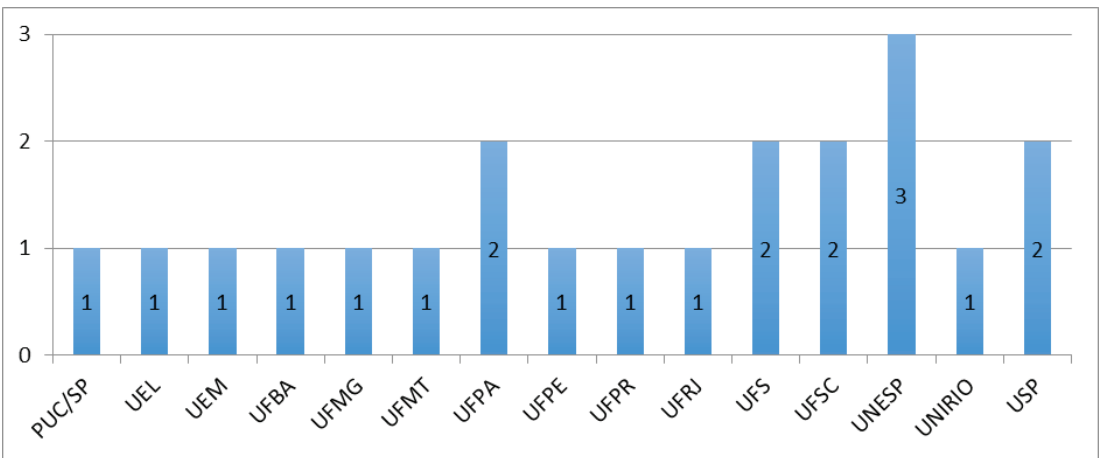

Fonte: Currículos Lattes dos autores pesquisados em http://lattes.cnpq.br/. Último acesso em: 4 jan. 2019.

No Sudeste, consta a predominância de autores oriundos dos estados de São Paulo e do Rio de Janeiro: seis (Bittencourt, Duarte, Melo Silva, Molina, Meirelles e Teruya) e dois (Soares e Rangel), respectivamente.

No nível de mestrado, a origem dos autores (Gráfico 7) é expressiva na Universidade Estadual Paulista "Júlio de Mesquita Filho", a Unesp: três nomes (Molina, Meirelles e Teruya). Também se destacam a Universidade de São Paulo: dois (Bittencourt e Silva); a Universidade Federal de Sergipe: dois (Oliveira e Lima); a Universidade Federal de Santa Catarina: dois (Costa e Dantas); e a Universidade Federal do Pará: dois (Silva e Ferreira). Sendo assim, a concentração institucional desse campo de estudo no mestrado envolve o estado de São Paulo, mais especificamente a USP e a Unesp.

Nota-se no Gráfico 8 que o número de autores que cursaram doutorado é menor em comparação com os níveis anteriores, já que apenas 17 obtiveram essa titulação.

Desse total, cinco o fizeram em Educação, nove cursaram em História/ História Social (Duarte, Molina, Meirelles, Abdala Junior, Bittencourt, Gerhardt, Ferreira, Santos e Trovão) e apenas um em Meio Ambiente (Lima). Novamente chama atenção a predominância de pesquisadores do campo da História. 
Gráfico 8 - Formação dos autores ENPEH (1995/2013): Cursos de Doutorado

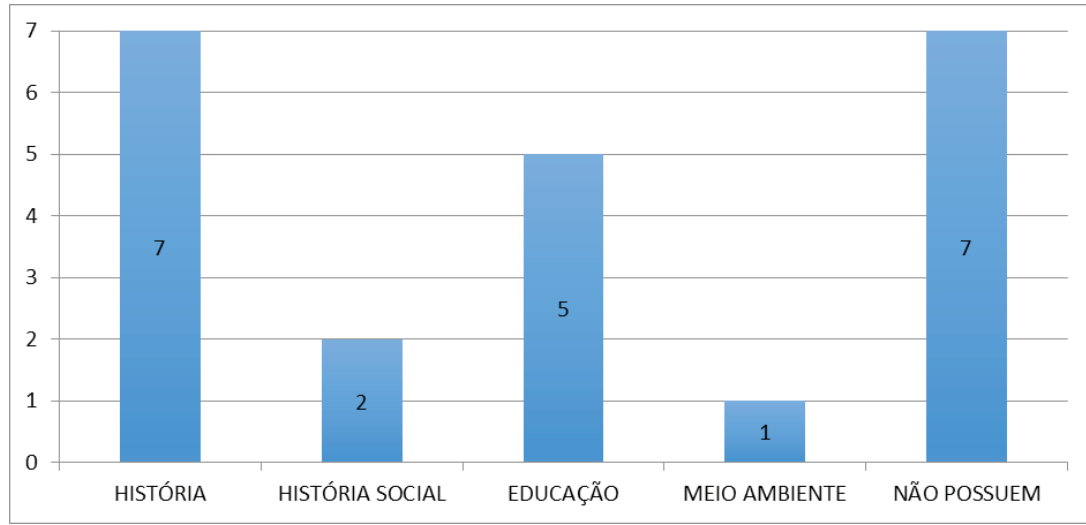

Fonte: Currículos Lattes dos autores pesquisados em http://lattes.cnpq.br/. Último acesso em: 4 jan. 2019.

Quadro 9 - Autores ENPEH (1995/2013) que cursaram Doutorado em História

\begin{tabular}{|l|l|}
\hline \multicolumn{1}{|c|}{ Autor } & \multicolumn{1}{c|}{ Título da tese } \\
\hline Duarte & Múltiplas Vozes no Ar: o rádio em São Paulo nos anos 30 e 40 \\
\hline Molina & $\begin{array}{l}\text { A influência das artes na civilização: Eliseu D’Angelo Visconti e } \\
\text { modernidade na Primeira República }\end{array}$ \\
\hline Meirelles & $\begin{array}{l}\text { Paródia \& Chanchada. Imagens do Brasil na Cultura das Classes } \\
\text { Populares }\end{array}$ \\
\hline Abdala Junior & Memórias da Ditadura Militar e os "rebeldes" anos oitenta \\
\hline Bittencourt & $\begin{array}{l}\text { Livro didático e conhecimento histórico: uma história do saber } \\
\text { escolar }\end{array}$ \\
\hline Gerhardt & História ambiental da erva-mate \\
\hline Ferreira & $\begin{array}{l}\text { Guerra sem fim: mulheres na trilha do direito à terra e ao destino } \\
\text { dos filhos (Pará - 1835-1860) }\end{array}$ \\
\hline Santos & A sedução da imagem: a televisão no limiar do Tocantins \\
\hline Trovão & O Exército Inútil de Robert Altman: cinema e política. (1983) \\
\hline
\end{tabular}

Fonte: Currículos Lattes dos autores pesquisados em http://lattes.cnpq.br/. Último acesso em: 4 jan. 2019. 
Quadro 10 - Autores ENPEH (1995/2013) que cursaram

Doutorado em Educação

\begin{tabular}{|l|l|}
\hline \multicolumn{1}{|c|}{ Autor } & \multicolumn{1}{c|}{ Título da Tese } \\
\hline Melo Silva & $\begin{array}{l}\text { Imagens Televisivas e Ensino de História: Representações Sociais e } \\
\text { Conhecimento Histórico }\end{array}$ \\
\hline Silva & $\begin{array}{l}\text { Configuraçães da Ação do Estado: um estudo sobre os processos de } \\
\text { regulação e avaliação das instituições de educação superior }\end{array}$ \\
\hline Dantas & $\begin{array}{l}\text { Espaços Coletivos de Esperança: A Experiência Política e } \\
\text { Pedagógica da Comissão de Educação do Fórum do Maciço do } \\
\text { Morro da Cruz em Florianópolis/SC }\end{array}$ \\
\hline $\begin{array}{l}\text { Luiz } \\
\text { Junior }\end{array}$ & $\begin{array}{l}\text { História da formação de professores no Brasil: análise crítica das } \\
\text { políticas de formação, por vídeos da década de 1990. }\end{array}$ \\
\hline Teruya & Trabalho e educação na era midiática: uma visão sociológica \\
\hline
\end{tabular}

Fonte: Currículos Lattes dos autores pesquisados em http://lattes.cnpq.br/. Último acesso em: 4 jan. 2019.

O Gráfico 8 permite observar ainda que, dos cinco que cursaram doutorado em Educação, nenhum deles tratou de cinema e ensino de História em sua tese (Quadro 10). Apenas três desses cinco autores se aproximaram desse campo de estudo, ao abordar: televisão (Melo Silva), vídeo como material de pesquisa (Luiz Junior) e era midiática (Teruya).

O Gráfico 9 indica instituições em que se fez o curso de doutorado. Destacam-se com três autores: a Pontifícia Universidade Católica de São Paulo (PUC-SP: Duarte, Ferreira e Luiz Junior) e a Universidade de São Paulo (USP: Bittencourt, Silva e Trovão). Com dois: a Universidade Federal de Santa Catarina (UFSC: Gerhardt e Dantas) e a Universidade Estadual Paulista (Unesp: Meirelles e Teruya).

Cada uma das demais conta com um autor: Universidade Federal do Ceará (UFC: Gomes); Universidade Federal Fluminense (UFF: Soares); Universidade Federal de Minas Gerais (UFMG: Abdala Junior); Universidade Federal do Paraná (UFPR: Molina); Universidade Federal de Pernambuco (UFPE: Santos); Universidade Federal do Sergipe (UFS: Lima); e Universidade Federal do Rio Grande do Sul (UFRGS: Silva).

Os autores que cursaram doutorado são oriundos de 11 universidades, a maioria delas situadas nas regiões Sul (três: UFSC, UFPR e UFRGS) e, 
Gráfico 9 - Formação dos autores ENPEH (1995/2013):

IES em que cursaram o doutorado

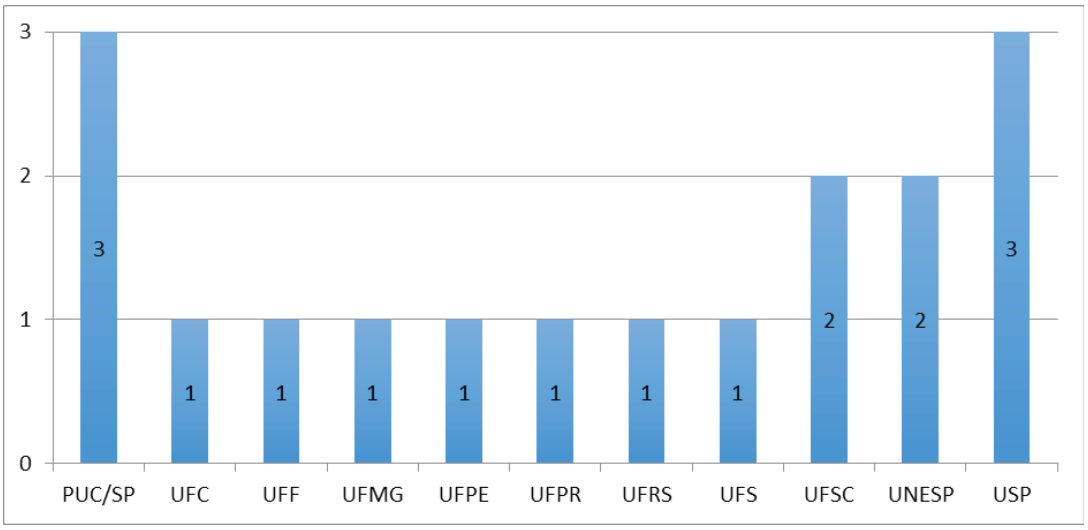

Fonte: Currículos Lattes dos autores pesquisados em http://lattes.cnpq.br/. Último acesso em: 4 jan. 2019.

especialmente, Sudeste (cinco: PUC/SP, USP, Unesp, UFF e UFMG), mais precisamente em São Paulo (com três das quatro IES com maior quantidade de autores, sendo elas responsáveis pela titulação de oito dos 17 que publicaram nas edições do ENPEH entre 1995 e 2013).

Como a maioria absoluta não abordou esse tema nem na dissertação nem na tese, pode-se constatar nessa concentração fator sociológico: trata-se da região mais urbanizada, mais densamente povoada e com maior quantidade de salas de cinema (em 2014, registrava-se que a região Sudeste ainda contava com 50\% dessas salas: 161 de 322 - IBGE, 2014).

Disso resulta que tais pesquisas envolvem mais significativamente a vivência desses autores do que suas formações acadêmicas. Por vivência devem ser pensados os contatos diretos com filmes, bem como as situações registradas em salas de aula nos mais diversos níveis de ensino. A cultura do vídeo tende a ser maior nos ambientes sociais em que a maioria dos autores pesquisados cursou graduação, mestrado e doutorado, podendo ser esse o fator explicativo para terem dedicado algum esforço a ele.

Cumpre também considerar que esses autores viveram na Educação Básica experiências em que o cinema é, de algum modo, considerado. É o caso do estado de São Paulo, onde foram registrados nas últimas três décadas dois 
projetos envolvendo cinema, o "Ceduc-vídeo" (Silva, 2009) e "O Cinema Vai à Escola" (Moura, 2013; Mogadouro, 2011).

A aludida cultura do vídeo constituiu espécie de saber experiencial dos autores que publicaram no ENPEH entre 1995 e 2013. Do ponto de vista de Freire (2010), esse saber pode ser identificado com algumas exigências das práticas educativas, caso de "estética e ética", "reflexão crítica sobre a prática", "curiosidade" e "liberdade e autoridade". Já do ponto de vista de Tardif (2002), esse saber pode ser interpretado como um dos elementos do trabalho docente, responsável por salientar o fato de ele ser essencialmente interativo.

Esse saber experiencial exerce papel importante, a ser devidamente reconhecido, tendo em vista que estimula a produção de textos sobre cinema e ensino de História, daí, novas práticas docentes (Imbernón, 2009). Contudo, por si só, não garante a constituição de campo forte de discussões acadêmicas, pois isso exige a presença de metodologias e epistemologias próprias, construídas a partir da promoção de diálogos (inter/multidisciplinares) mais intensos entre História, cinema, educação e ensino, segundo a relação escola-universidade.

A maior parte dos trabalhos envolvendo ensino de História e cinema publicados nas edições do ENPEH 1995/2013 foi elaborada por autores pertencentes ao campo da História - isso porque a maioria cursou História na graduação, mestrado e doutorado. Considerando o exposto por Michel de Certeau (1982), ao enfatizar a História como produto de lugar social, podemos considerar que esses trabalhos também obedecem a certas regras institucionais implícitas. No campo de estudo da História, o tema "cinema e ensino de História” parece não ser privilegiado e validado tanto quanto outros.

Foram selecionados 19 textos envolvendo cinema e ensino de História, produzidos por 24 autores. A análise do currículo Lattes permitiu identificar que a maioria (18) cursou graduação em História. No nível de Pós-Graduação repetiu-se a predominância da formação em História, já que nove apresentaram dissertação, e outros nove, tese nesse campo. Observados todos esses trabalhos (dissertações e teses), constatou-se ainda que nenhum deles foi dedicado especificamente ao tema "cinema e ensino de História"; na realidade, nenhum envolveu sequer o cinema ou o ensino de História.

Essa ausência, somada às marcas do lugar social da História, perfazem, em boa medida, os motivos pelos quais os textos publicados no ENPEH sobre 
cinema apresentam abordagem correspondente, essencialmente, aos conteúdos, posto que tratam dos filmes, ressaltando os temas/assuntos de História que poderiam ser refletidos nessas obras, sem se dedicarem ou pouco se dedicando aos modos como deveriam ser processadas as estratégias de ensino e de aprendizagem.

Quadro 11 - Objetivos dos trabalhos apresentados no ENPEH

\begin{tabular}{|l|l|}
\hline \multicolumn{1}{|c|}{ Objetivos } & \multicolumn{1}{c|}{ Autores } \\
\hline $\begin{array}{l}\text { Conteúdo e material } \\
\text { pedagógico }\end{array}$ & $\begin{array}{l}\text { Soares (1995); Silva (1999); Gerhardt (1999); } \\
\text { Molina (2003); Melo Silva (2003); Meirelles } \\
\text { (2006); Melo Silva (2008); Meirelles (2008); Luiz } \\
\text { Junior e Teruya (2008), Oliveira (2013), Moura da } \\
\text { Silva (2013) e Ribeiro dos Santos e Trovão (2013). }\end{array}$ \\
\hline Metodologia pedagógica & $\begin{array}{l}\text { Bittencourt (1995); Gerhardt (1999); Silva (1999); } \\
\text { Ferreira (2003); Gomes (2003); Duarte (2003); } \\
\text { Abdala Junior (2006); Meirelles (2008), Santos } \\
\text { (2013), Lima (2013) }\end{array}$ \\
\hline $\begin{array}{l}\text { Alfabetização } \\
\text { cinematográfica }\end{array}$ & $\begin{array}{l}\text { Silva (1999); Gerhardt (1999); Dantas; Costa; } \\
\text { Rangel; Frazzi; Fortes (2006) }\end{array}$ \\
\hline Produção fílmica & Santos (2013) \\
\hline
\end{tabular}

Fonte: Anais do ENPEH (1993/2013). Alguns autores expressam mais de um objetivo.

A preocupação majoritária (12 trabalhos) com o conteúdo e com o material pedagógico diz respeito a textos que se dedicaram a utilizar o cinema para trabalhar com determinado tema ou assunto pertencentes à disciplina de História (sejam eles envolvendo acontecimentos históricos ou conceitos históricos), indicando filmes considerados adequados para cumprimento desse propósito.

Reflexões a respeito da metodologia pedagógica também aparecem em bom número de textos pesquisados (dez trabalhos), mas tratam do estado da arte envolvendo o tema "uso do cinema em sala de aula" ou promovem discussões sobre certos aspectos (realização de debates; leituras das imagens; compreensão das visões de mundo; organização de coletânea de imagens fílmicas 
e de manual; associação entre filmes e representações do passado; utilização do filme como ferramenta didática etc.), sem mencionar como fazer isso.

O que se denomina por "Alfabetização cinematográfica" (três trabalhos) envolve o reconhecimento de textos que se dedicam a problematizar a importância da abordagem de aspectos dessa linguagem (roteiro, enredo, montagem, cortes, ficha técnica, posicionamento de câmera etc.), colaborando para que essa arte possa ser mais bem entendida pelos alunos, embora ainda revelem preocupação com a abordagem de determinado assunto.

Já a preocupação com a "Produção fílmica" é objeto em início de enfrentamento nesse campo de pesquisa (apenas um trabalho) e envolve a construção de obras dessa natureza com/pelos alunos, de modo a promover ampla apropriação pedagógica desses vídeos, pois, ao serem produzidos, busca-se: enfrentar determinado tema/assunto histórico; pensar em métodos para empregar o cinema; e erigir a discussão do cinema como linguagem. O segundo maior grupo de titulações obtidas pelos autores que publicaram sobre cinema e ensino de História nas edições do ENPEH analisadas envolve o campo da Educação. Nota-se, porém, que do total de 13 trabalhos (oito dissertações e cinco teses), apenas três tratam dessa temática e outros dois abordam temáticas próximas (televisão e mídia). Sendo assim, o enfrentamento do debate ensino de História e cinema não está majoritariamente associado a pesquisas desenvolvidas durante a formação na Pós-Graduação em Educação.

\section{CONSIDERAÇÕES FINAIS}

Com o intuito de compreender como o cinema é pensado no ensino de História, foram perscrutados os Anais do Encontro Nacional dos Pesquisadores de Ensino de História (ENPEH) entre 1995 e 2013. O evento acontece bianualmente, desde 1993, e possibilita a troca de experiências entre os pesquisadores, além de oportunizar a ampliação do aprofundamento da problemática referente a temas, procedimentos metodológicos, fontes de pesquisa e referenciais teóricos empregados nas pesquisas do campo do ensino de História.

Autores que produziram textos voltados ao tema "cinema e ensino de História” tiveram sua trajetória acadêmica analisada. Seus currículos Lattes foram empregados para entender o grau e a qualidade de envolvimento com a temática estudada, por meio da análise de aspectos como participação em 
projetos de pesquisa, publicações e apresentação de trabalhos em outros eventos. Refletiu-se igualmente sobre a formação desses autores em nível de graduação, mestrado e doutorado, identificando as IES frequentadas, bem como os temas pesquisados.

As reflexões desses autores merecem respeito. Contudo, representam zona de enfrentamento com trabalhos cujo número é constante, mas ainda tímido. Além disso, em boa medida, eles estão dissociados de pesquisas de mestrado e de doutorado, bem como não fazem parte de iniciativas de grupos ou são temas de projetos de pesquisa específicos. Esse panorama sugere o emprego de filmes mais como material didático em sala do que tema de pesquisa no ensino de história.

Nota-se, igualmente, que os autores desses trabalhos desenvolveram formação acadêmica concentrada em IES situadas no Sudeste. Dado que esses trabalhos não se ancoram em situações acadêmicas como as aqui citadas, depreende-se indício de que o enfrentamento do tema "cinema e ensino de História” está associado aos grandes centros urbanos e a determinadas experiências sociológicas e de práticas de sala de aula. Isso não diminui em nada o valor desses trabalhos, mas é outro dado que referenda a constatação da falta de consistência desse campo de estudo.

As pesquisas associadas ao ensino de História e cinema revelam marcas dos campos de estudo de História e de Educação. Em História não foi possível identificar nenhuma pesquisa desenvolvida sobre ensino, apenas a respeito de filmes. Já em Educação nota-se praticamente o contrário, ou seja, pesquisas voltadas a filmes, mas que não tratam do ensino de História. Essa falta de diálogo entre as perspectivas dos dois campos (conteúdo e metodologia) parece revelar dilema estrutural da formação de professores no Brasil e contribui para que não ocorra maior fortalecimento dos estudos sobre cinema e ensino de História.

Passados mais de 120 anos da invenção do cinema e em momento no qual os vídeos estão cada vez mais presentes no cotidiano, considera-se preocupante tal situação. O ensino fílmico da História se apresenta como fundamental para o diálogo com os alunos, a constituição de outros olhares e a valorização das especificidades sociais (especialmente se pensarmos na produção de vídeos). Cinema digital, tecnologia streaming e a popularização de smartphones pressionam e, ao mesmo tempo, proporcionam respostas nesse sentido, uma vez 
que tornaram os filmes ainda mais presentes no cotidiano social, dada a popularização de consumo e produção gerada.

Nos últimos anos, novos fatores, como a Lei 13.006/2014 (que trata da exibição de filmes nacionais como componente curricular), a expansão de Programas de Pós-Graduação nas áreas de Educação e de Ensino, bem como a criação do ProfHistória (Programa de Pós-Graduação Profissional ofertado em rede nacional) dotam o cinema de novas oportunidades tanto no ensino como na pesquisa.

\section{REFERENNCIAS}

ALVES-MAZZOTTI, Alda J.; GEWANDSZNAJDER, Fernando. O método nas ciências naturais e sociais. São Paulo: Pioneira, 1999.

ARAÚJO FILHO, Waldemir de. Cinema e ensino de História na perspectiva de professores de História. 2007. Dissertação (Mestrado em Educação) - Pontifícia Universidade Católica do Rio de Janeiro (PUC-Rio). Rio de Janeiro, 2007.

AUMONT, Jacques. O olho interminável. São Paulo: Cosac \& Naify, 2004.

BARBOSA JÚNIOR, Alberto L. Arte da Animação: técnica e estética através da História. São Paulo: Ed. Senac, 2002.

BELLONI, Maria Luiza; BÉVORT, Evelyne. Mídia-educação: conceitos, história e perspectivas. Educação \& Sociedade, v. 30, p. 1081-1102, 2009.

BOURDIEU, Pierre. A Economia das trocas simbólicas. São Paulo: Perspectiva, 2011.

BOURDIEU, Pierre. Para uma sociologia da ciência. Lisboa: Edição 70, 2004.

BITTENCOURT, Circe M. F. Ensino de História: fundamentos e métodos. São Paulo: Cortez, 2008.

BITTENCOURT, Circe M. F. O saber histórico na sala de aula. São Paulo: Contexto, 2006.

CABRERA, Julio. O cinema pensa: uma introdução à filosofia através dos filmes. Rio de Janeiro: Rocco, 2006.

CAPELATO, Maria Helena et al. (org.). História e cinema. São Paulo: Alameda, 2007.

CATELLI, Rosana Elisa. Dos "naturais" ao documentário: o cinema educativo e a educação do cinema, entre os anos 1920 e 1930. 2007. Tese (Doutorado em Multimeios) - Instituto de Artes (IA), Universidade Estadual de Campinas (Unicamp). Campinas, 2007.

CERTEAU, Michel de. A operação histórica. In: CERTEAU, Michel de. A escrita da história. Rio de Janeiro: Forense, 1982, p. 65-119. 
CRARY, Jonathan. Techniques of the Observer: On Vision and Modernity in the Modernity in the Nineteenth Century. Cambridge, MA: MIT Press, 1995.

CERTEAU, Michel de. A operação histórica. In: CERTEAU, Michel de. A escrita da história. Rio de Janeiro: Forense, 1982, p. 65-119.

DUARTE, Rosália. Cinema \& educação. Belo Horizonte: Autêntica, 2002.

FALCÃO, Antônio R; BRUZZO, Cristina (org.). Lições com cinema. São Paulo: FDE, 1993.

FANTIN, Monica. Crianças, cinema e mídia-educação: olhares e experiências no Brasil e na Itália. 2006. Tese (Doutorado em Educação) - Universidade Federal de Santa Catarina (UFSC). Florianópolis, 2006.

FERRO, Marc. Cinema e História. São Paulo: Paz e Terra, 2010.

FISCHER, Rosa Maria B. Docência, cinema e televisão: questões sobre formação ética e estética. Revista Brasileira de Educação, v. 14, n. 40, p. 93-102, jan./abr. 2009.

FONSECA, Selva G. Caminhos da história ensinada. Campinas: Papirus, 1993.

FONSECA, Selva G. Didáticas e prática de ensino de História. Campinas: Papirus, 2003.

FREIRE, Paulo. Pedagogia da autonomia: saberes necessários à prática educativa. São Paulo: Paz e Terra, 2010.

FRESQUET, Adriana M. Cinema e educação: reflexões e experiências com professores e estudantes de educação básica, dentro e "fora" da escola. Belo Horizonte: Autêntica, 2013.

GAMBOA, Silvio S. (org.). Pesquisa educacional: quantidade-qualidade. São Paulo: Cortez, 1997.

GIL, Antonio Carlos. Como elaborar projetos de pesquisa. São Paulo: Atlas, 2007.

GIL, Antonio Carlos. Métodos e técnicas de pesquisa social. São Paulo: Atlas, 1994.

GINZBURG, Carlo. O fio e os rastros: verdadeiro, falso, fictício. São Paulo: Companhia das Letras, 2007b.

GINZBURG, Carlo. A micro-história e outros ensaios. Lisboa: Difel, 1989.

GINZBURG, Carlo. Mitos, emblemas e sinais: morfologia e história. São Paulo: Companhia das Letras, 2007a.

IMBERNÓN, Francisco. Formação permanente do professorado: novas tendências. São Paulo: Cortez, 2009.

KENSKI, Vani Moreira. O ensino e os recursos didáticos em uma sociedade cheia de tecnologias In: VEIGA, I. P. A. Didática: o ensino e suas relações. Campinas: Papirus, 1996. p. 127-147. 
MARCELLO, Fabiana de A. Real versus ficção: criança, imagem e regimes de credibilidade no cinema-documentário. Educação revista, v. 26, n. 3, p. 129-149, 2010.

MEDEIROS, Carlos Augusto de. Estatística aplicada à educação. Brasília: Ed. UnB, 2007.

MESQUITA, Ilka M. de. ENPEH: espaço de diálogo da pesquisa de ensino de história. In: ENCONTRO NACIONAL DOS PESQUISADORES DO ENSINO DE HISTÓRIA, 9., 2011, Florianópolis. América Latina em perspectiva: culturas, memórias e saberes. Anais... Florianópolis: UFSC/CED, 2011. v. 1, p. 1-20.

MINAYO, Maria Cecília de S. (org.). Pesquisa Social: teoria, método e criatividade. Petrópolis: Vozes, 2000.

MOGADOURO, Claudia de A. Educomunicação e escola: o cinema como mediação possível (desafios, práticas e proposta). 2011. Tese (Doutorado) - Escola de Comunicações e Artes (ECA), Universidade de São Paulo (USP). São Paulo, 2011.

MONTEIRO, Ana N. O cinema educativo como invocação pedagógica na escola primária paulista (1933-1944). 2006. Dissertação (Mestrado em Educação) - Faculdade de Educação (FE), Universidade de São Paulo (USP). São Paulo, 2006.

MORIN, Edgar. O cinema ou o homem imaginário. Lisboa: Relógio D’Água: Grande Plano, 1997.

MOURA, Marcilene Rosa L. O cinema como prática educativa no ensino médio: Projeto "O Cinema vai à escola". 2013. Tese (Doutorado em Educação) - Universidade Federal de São Carlos (UFSCar). São Carlos, 2013.

NAPOLITANO, Marcos. Como usar o cinema na sala de aula. São Paulo: Contexto, 2008.

NASCIMENTO, Jairo C. do. Cinema e ensino de história: realidade escolar, propostas e práticas na sala de aula. Fênix - Revista de História e Estudos Culturais, ano V, v. 5, n. 2, abr./maio/jun. 2008.

NOVAES, Adauto (org.). O olhar. São Paulo: Companhia da Letras, 1997.

NÓVOA, Jorge; BARROS, José d'A. Cinema-história: teoria e representações sociais no cinema. Rio de Janeiro: Apicuri, 2008.

NÓVOA, Jorge; FRESSATO, Soleni B.; FEIGELSON, Kristian (org.). Cinematógrafo: um olhar sobre a história. São Paulo: Ed. Unesp, 2009.

POURRIOL, Ollivier. Cinéfilo. Rio de Janeiro: Jorge Zahar, 2009.

RANCIÈRE, Jacques. O espectador emancipado. São Paulo: Martins Fontes, 2012.

RANCIÈRE, Jacques. A fabula cinematográfica. Campinas: Papirus, 2013.

RANCIÈRE, Jacques. A partilha do sensivel: estética e política. São Paulo: Editora 34, 2005. 
ROSENSTONE, Robert. A história nos filmes, os filmes na história. São Paulo: Paz e Terra, 2010.

SALIBA, Maria Eneida F. Cinema contra cinema. São Paulo: Annablume: Fapesp, 2003.

SAVIANI, Dermeval. Formação de professores: aspectos históricos e teóricos do problema no contexto brasileiro. Revista Brasileira de Educação, v. 14, p. 143-155, 2009.

SCHWARTZ, Vanessa R.; CHARNEY, Leo. O cinema e a invenção da vida moderna. São Paulo, Cosac-Naify, 2001.

SETTON, Maria da Graça J. Mídia e educação. São Paulo: Contexto, 2010.

SETTON, Maria da Graça J. (org.). A cultura da mídia na escola: ensaios sobre cinema e educação. São Paulo: Annablume, 2004.

SILVA, Marcos; FONSECA, Selva G. Ensinar história no século XXI. Campinas: Papirus, 2007.

SILVA, Marcos; RAMOS, Alcides F. (org.). Ver história: o ensino vai aos filmes. São Paulo: Hucitec, 2011.

SIMAN, Lana Mara C.; RICCI, Claudia Regina F. M. S. (org.). ENPEH: Novos problemas, novas abordagens. Encontro Nacional dos Pesquisadores do Ensino de História. Anais... Belo Horizonte: FAE/UFMG, 2006.

SORLIN, Pierre. Indispensáveis e enganosas, as imagens, testemunhas da história. Estudos históricos, Rio de Janeiro, v. 7, n. 13, p. 81-95, 1994.

SORLIN, Pierre. Sociología del Cine: la apertura para la historia de mañana. México: Fondo de Cultura Económica, 1985.

TARDIF, Maurice. Saberes docentes e formação profissional. Rio de Janeiro: Vozes, 2002.

TRIVIÑOS, Augusto Nibaldo S. Introdução à pesquisa em ciências sociais: a pesquisa qualitativa em educação. São Paulo: Atlas, 1992.

\section{Fontes documentais}

ENPEH. Anais do Encontro Nacional dos Pesquisadores do Ensino de História $(1995 / 2013)$.

\section{Fontes digitais}

CURRÍCUlO LATTES de Circe Maria Fernandes Bittencourt, Mariza de Carvalho Soares, Tattiana Tessye Freitas da Silva, Marcos Gerhardt, Geni Rosa Duarte, Eliana Ramos Ferreira, Elane Cristina Rodrigues Gomes, André Chaves de Melo Silva, Ana Heloísa Molina, William Reis Meirelles, Roberto Abdala Junior, José 
Fernandes Costa, Ana Paula Rangel, Mariana Ziloti Frazzi, Marina Gabriela Fortes, Jeferson Silveira Dantas, Celso Luiz Junior, Teresa Kazuko Teruya, Daiane de Jesus Oliveira, Eliakin Ramos Moura da Silva, Jocyleia Santana dos Santos, Luis Eduardo Pina Lima, Ronaldo Alves Ribeiro dos Santos, Flavio Villas Boas Trovão, Elias Thomé Saliba, Katia Maria Abud, Jairo de Carvalho Nascimento, Marcos Napolitano e Roger Chartier, todos disponíveis em http://lattes.cnpq.br/web/ plataforma-lattes/

IBGE. https://ww2.ibge.gov.br/home/estatistica/economia/perfilmunic/cultura_2014/ default.shtm

INEP. Sinopse Estatística da Educação Superior 2017. http://portal.inep.gov.br/ sinopses-estatisticas-da-educacao-superior

Artigo recebido em 4 de maio de 2019. Aprovado em 11 de dezembro de 2019. 